\title{
Translation and Psychometric Evaluation of the Dutch Families Importance in Nursing Care: Nurses Attitudes Scale Based on the Generalized Partial Credit Model
}

E. I. Hagedoorn, W. Paans, Tiny J aarsma, J . C. Keers, C. P. van der Schans, M. L. Luttik and W. P. Krijnen

The self-archived postprint version of this journal article is available at Linköping University Institutional Repository (DiVA):

http:/ / urn.kb.se/ resolve?urn=urn:hbn:se:liu:diva- 153702

N.B.: When citing this work, cite the original publication.

Hagedoorn, E. I., Paans, W., J aarsma, T., Keers, J . C., van der Schans, C. P., Luttik, M. L., Krijnen, W. P., (2018), Translation and Psychometric Evaluation of the Dutch Families Importance in Nursing Care: Nurses Attitudes Scale Based on the Generalized Partial Credit Model, J ournal of Family Nursing, 24(4), 538-562. https:// doi.org/ 10.1177/ 1074840718810551

Original publication available at:

https:/ / doi.org/ 10.1177/ 1074840718810551

Copyright: SAGE Publications (UK and US)

http:// www.uk.sagepub.com/home.nav 


\title{
Translation and Psychometric Evaluation of the Dutch Families
}

\section{Importance in Nursing Care - Nurses’ Attitudes Scale based on the Generalized Partial Credit Model}

\author{
E.I. Hagedoorn, RN, MSc ${ }^{\text {a,b,c }}$ \\ W. Paans, RN, PhD ${ }^{\mathrm{c}}$ \\ T. Jaarsma, RN, PhD ${ }^{d}$ \\ J.C. Keers, $\mathrm{PhD}^{\text {a,e }}$ \\ C.P. van der Schans, PT, CE, PhD ${ }^{\text {a,b,f }}$ \\ M.L Luttik, RN, PhD ${ }^{\text {c }}$ \\ W.P. Krijnen, $\mathrm{PhD}^{\text {a,g }}$ \\ a Research group healthy ageing, allied health care and nursing, Hanze university of applied sciences, P.O. Box 3109, 9701 DC Groningen, \\ the Netherlands. Phone: +31(0) 50 5953539. E-mail: c.p.van.der.schans@pl.hanze.nl \\ b University of Groningen, University Medical Center, department of health psychology, A. Deusinglaan 1, 9713AV Groningen, the \\ Netherlands. \\ c Research group nursing diagnostics, Hanze university of applied sciences, P.O. Box 3109, 9701 DC Groningen, the Netherlands. W. Paans \\ Phone: +31(0)651979573. E-mail: w.paans@pl.hanze.nl; ML. Luttik Phone: +31 (0)640585983. E-mail: m.l.a.luttik@pl.hanze.nl \\ d Department of social and welfare studies (ISV), Linköping University, SE-581 83 Linköping Sweden and Mary Mackillop Institute for Health \\ Research Australian Catholic University, Melbourne, Australia. Phone: +46 11363550. E-mail: tiny.jaarsma@liu.se \\ e Martini hospital Groningen, Research Institute, PO Box 30033, 9700 RM Groningen, the Netherlands. Phone: +31(0)50 52458276 E-mail: \\ J.Keers@mzh.nl \\ f University of Groningen, University Medical Center, department of rehabilitation, A. Deusinglaan 1, 9713AV Groningen, the Netherlands. \\ g Faculty of science and engineering, Johan Bernoulli Institute, University of Groningen, PO Box 72, 9700 AB Groningen, the Netherlands. \\ Phone: +31(0)50 3633780. E-mail: w.p.krijnen@pl.hanze.nl
}

Corresponding author: Ellen I. Hagedoorn, Hanze University of Applied Sciences, P.O. Box 3109, 9701 DC Groningen, the Netherlands. Tel: +31 (0)657328748. Email address: e.i.hagedoorn@pl.hanze.nl

\section{Keywords}

Family; Instrument (FINC-NA); Nurses’ attitudes; Psychometrics; Rasch model 


\section{Bibliographical Paragraph}

\section{Ellen I. Hagedoorn, RN, MSc, PhD Candidate}

Research group Healthy Ageing, Allied Health Care and Nursing and School of Nursing, Hanze University of Applied Sciences and University of Groningen, University Medical Center, department of Health Psychology, Groningen, the Netherlands. Research interest: Involvement and collaboration of family caregivers of older people ( $>70$ years) with chronic conditions, self-management of older people. Publication:

Hagedoorn, E.I., Paans, W., Jaarsma, T., Keers, J.C., van der Schans, C.P., \& Luttik, ML.A. (2017). Aspects of family caregiving as addressed in planned discussions between nurses, patients with chronic diseases and family caregivers: a qualitative content analysis. BMC Nursing. doi: 10.1186/s12912-017-0231-5

\section{Wolter Paans, RN, PhD}

Research group Nursing Diagnostics, Hanze University of Applied Sciences, Groningen, the Netherlands. Research in the diagnostic reasoning process, as well as in systemic and dynamic communication, documentation and hand over using supporting electronic documentation systems. Publications:

Paans, W., Robbe, P., Wijkamp, I. \& Wolfensberger, M.V.C. (2017) What establishes an excellent nurse? A focus group and Delphi panel approach. BMC Nursing doi: 10.1186/s12912-017-0239-X.

Tuinman, A., Greef, de, M., Paans, W., \& Roodbol, P.F. (2017) Accuracy of documentation in the nursing care plan in long-term institutional care. Geriatric Nursing. Vol. 38(6), 578-583. doi: 10.1016/j.gerinurse.2017.04.007

\section{Tiny Jaarsma, RN, PhD}

Professor, Department of social and welfare studies (ISV), Linköping University, SE-581 83 Linköping Sweden and Professorial Fellow Mary Mackillop Institute for Health Research Australian Catholic University, Melbourne, Australia. Research and clinical interests: improving heart failure care, chronic disease management, self-care in chronic illness Relevant publications: 
Liljeroos, M. Ågren, S., Jaarsma, T., Stromberg, A (2017). Dialogues between nurses, patients with heart failure and their partners during a dyadic psychoeducational intervention: a qualitative study. BMJ Open. 7: e018236. doi:10.1136/bmjopen-2017-018236

Kato, N.P., Okada, I., Kagami, Y., Endo, M., Hatano, M., Ono, M., Jaarsma, T., \& Kinugawa, K (2018). Quality of life of family caregivers of patients with a left ventricular assist device in Japan. J Cardiol. 71(1):81-87. doi: 10.1016/j.jjcc.2017.06.004.

Strömberg, A., Bonner, N., Grant, L., Bennett, B., Chung, M.L., Jaarsma, T., Luttik. M.L., Lewis, E.F., Calado, F., \& Deschaseaux, C. (2017). Psychometric Validation of the Heart Failure Caregiver Questionnaire (HF-CQ®). Patient. 10(5):579-592. doi: 10.1007/s40271-017-0228-x.

\section{Joost C. Keers, PhD}

Head of Research Institute at Martini Hospital Groningen and professor of applied science at Research group Healthy Ageing, Allied Health Care and Nursing, Hanze University of Applied Sciences, Groningen, the Netherlands. Research and clinical interests: Selfmanagement of patients with somatic illness, in particular in older patients in a hospital setting. Ethical and organisational aspects of clinical studies in hospitals. Evidence Based Practice for nursing staff. Publications:

Hagedoorn, E.I., Paans, W., Jaarsma, T., Keers, J.C., van der Schans, C.P., \& Luttik, ML.A. (2017). Aspects of family caregiving as addressed in planned discussions between nurses, patients with chronic diseases and family caregivers: a qualitative content analysis. $B M C$ Nursing. doi: 10.1186/s12912-017-0231-5

Goot, van der, W.E., Keers, J.C., Kuipers, R., Nieweg, R.M.B., \& Groot, de, M. (2018) The effect of a multifaceted evidence-based practice programme for nurses on knowledge, skills, attitudes, and perceived barriers: A cohort study. Nurse Educ Today. Apr; 63: 611. doi:10.1016/j.nedt.2018.01.008

\section{Cees P. van der Schans, PT, CE, PhD}

Research group Healthy Ageing, Allied Health Care and Nursing, Hanze University of Applied Sciences and University of Groningen, University Medical Center, department of health psychology and department of rehabilitation, Groningen, the Netherlands.

Graduated as a physical therapist (1978) and clinical epidemiologist (1999) and is currently professor Healthy Ageing, Allied Health Care and Nursing, at the Hanze University of 
Applied Sciences and professor Rehabilitation Medicine University Hospital Groningen. Publications:

Ter Beek, L., Vaart, van der, H., Wempe, J.B., Dzialendzik, A.O., Roodenburg, J.L., Schans, van der, C.P., Keller, H.H., \& Jager-Wittenaar, H. (2018). Dietary resilience in patients with severe COPD at the start of a pulmonary rehabilitation program. Int J Chron Obstruct Pulmon Dis. Apr 23;13:1317-1324. doi: 10.2147/COPD.S151720

Willems, M., Waninge, A., Hilgenkamp, T.I.M., Empelen, van, P., Krijnen, W.P., Schans, van der, C.P., \& Melville, C.A. (2018). Effects of lifestyle change interventions for people with intellectual disabilities: Systematic review and meta-analysis of randomized controlled trials. J Appl Res Intellect Disabil. May 8. doi: 10.1111/jar.12463

Adrichem, van, E.J., Dekker, R., Krijnen, W.P., Verschuuren, E.A.M., Dijkstra, P.U., Schans, van der, C.P. (2018). Physical Activity, Sedentary Time, and Associated Factors in Recipients of Solid-Organ Transplantation. Phys Ther. May 10. doi: 10.1093/ptj/pzy055

\section{Marie Louise A. Luttik, RN, PhD}

Research group Nursing Diagnostics, Hanze University of Applied Sciences, Groningen, the Netherlands. Dr. M.L.Luttik is a senior researcher affiliated at the Hanze University of Applied Sciences, Research Group Nursing Diagnostics. She is an experienced researcher with a focus on Family Care and Family Nursing. Her research interest includes Family Health Care Nursing over the full lifespan ranging from the care for newborn infants to care at the end-of-life. Publications:

Hagedoorn, E.I., Paans, W., Jaarsma, T., Keers, J.C., van der Schans, C.P., \& Luttik, ML.A. (2017). Aspects of family caregiving as addressed in planned discussions between nurses, patients with chronic diseases and family caregivers: a qualitative content analysis. BMC Nursing. doi: 10.1186/s12912-017-0231-5

Strömberg, A. \& Luttik, M.L. (2015). Burden of caring: risks and consequences imposed on caregivers of those living and dying with advanced heart failure. Curr Opin Support Palliat Care. Mar;9(1):26-30. doi: 10.1097/SPC.0000000000000111.

Näsström, L., Luttik, M.L., Idvall, E., \& Strömberg, A. (2017). Exploring partners' perspectives on participation in heart failure home care: a mixed-method design. $J$ Adv Nurs. May;73(5):1208-1219. doi: 10.1111/jan.13216. 


\section{Wim P. Krijnen, PhD}

Research group Healthy Ageing, Allied Health Care and Nursing, Hanze University of Applied Sciences and Faculty of science and engineering, University of Groningen, Groningen, the Netherlands. Expert in the field of Statistics \& Probability. Publications:

Adrichem, van, E. J., Dekker, R., Krijnen, W. P., Verschuuren, E. A. M., Dijkstra, P. U. \& Schans, van der, C. P. (2018). Physical Activity, Sedentary Time, and Associated Factors in Recipients of Solid-Organ Transplantation. Physical Therapy. pzy055 doi: 10.1093/ptj/pzy055

Drenth, H., Zuidema, S. U., Krijnen, W. P., Bautmans, I., Smit, A. J., Schans, van der C.P., \& Hobbelen, H. (2018). Advanced Glycation End-products are associated with Physical Activity and Physical Functioning in the older population. Journal of Gerontology: Medical sciences. doi: 10.1093/gerona/gly108

\footnotetext{
Abstract

The Families Importance in Nursing Care- Nursing Attitudes instrument is used to measure nurses' attitudes towards families. The aim of this study is to evaluate the FINC-NA scale in a population of Dutch nurses and add new psychometric information to existing knowledge. Using a cross sectional design, 1,211 nurses received an online application in 2015. Psychometric properties were based on Polychoric correlations and the Generalized Partial Credit Model. A total of 597 (49\%) nurses responded. Results confirmed a four-subscale structure. All response categories were utilized, although some ceiling effects occurred. Most items increase monotonically, and the majority of items discriminate well between different latent trait scores of nurses with some items providing more information than others. This study shows good psychometric properties of the Dutch FINC-NA instrument. New insights into the construct and content of items enable generating a more generic instrument that could be valid across several cultures.
} 
Family members have considerable influence on the health and self-care of elderly individuals with chronic diseases (Gallagher, Luttik, \& Jaarsma, 2011; Hartmann, Bazner, Wild, \& Eisler, 2010; Wu, et al., 2012). Therefore, it is important for nurses to involve family members in nursing care to promote continuity of care for the patient (Bridges, Flatley, \& Meyer, 2010; Lowson, et al., 2013) and collaborate with them as partners in care (Lindhardt, Nyberg, \& Rahm Hallberg, 2008; Wassenaar, Schouten, \& Schoonhoven, 2014).When nurses have a more positive attitude towards families, they are more likely to involve families in nursing care (Hsiao \& Tsai, 2015; Rahmqvist Linnarsson, Benzein, \& Arestedt, 2014). A widely used instrument to measure nurses’ attitudes towards involvement of family members is the Families Importance in Nursing Care - Nursing Attitudes (Benzein, Johansson, Årestedt, Berg, \& Saveman, 2008) (Saveman, Benzein, Engström, \& Årestedt, 2011).

The Families Importance in Nursing Care - Nurses’ Attitudes (FINC-NA) instrument has been employed to assess nurses’ attitudes toward families in nursing care (Angelo, et al., 2014; Benzein, Johansson, Årestedt, \& Saveman, 2008; Luttik, et al., 2017; Rahmqvist Linnarsson, et al., 2014; Skúladóttir, Konráđsdóttir, \& Ágústsdóttir, 2010) and to measure the effect of educational types of program interventions on the attitudes of nurses (Blöndal, et al., 2014; Lindh, et al., 2013; Sveinbjarnardottir, Svavarsdottir, \& Saveman, 2011). Since its initial use in 2008 in Sweden (Benzein, Johansson, Årestedt, Berg, \& Saveman, 2008), the FINC-NA has also been widely used in other countries, e.g., Iceland (Skúladóttir, Konráðsdóttir, \& Ágústsdóttir, 2010), Portugal (Fernandes, Pereira Gomes, Martins, Pereira Gomes, \& Hisako, 2015; Nunes Carramanho Gomes Martins Moreira da Silva, da Silva Mendes da Costa, \& Ferreira Pereira da Silva, 2013; Oliveira, et al., 2011), Spain (Pascual Fernández , Cervantes Estévez , Jiménez Carrascosa , Medina Torres , \& García Pozo , 2015), Taiwan (Hsiao \& Tsai, 2015), Denmark, Norway, Belgium (Luttik, et al., 2017), and Australia (Mackie, Marshall, Mitchell, \& Ireland, 2017) (Table 1). 
Table 1. FINC-NA used in studies and reported psychometric properties

\begin{tabular}{|c|c|c|c|c|c|c|c|c|c|c|}
\hline Author & Country & Nurses sample & & $\begin{array}{l}\text { Likert } \\
\text { scale }\end{array}$ & $\begin{array}{l}\text { Numberof } \\
\text { Subscales }\end{array}$ & $\begin{array}{l}\text { Cronbach's } \\
\text { alpha's }\end{array}$ & $\begin{array}{l}\text { Factor } \\
\text { loadings }\end{array}$ & $\begin{array}{c}\text { Scale } \\
\text { dimensions }\end{array}$ & $\begin{array}{c}\text { Distribution } \\
\text { of scores }\end{array}$ & $\begin{array}{c}\text { Item total } \\
\text { correlations }\end{array}$ \\
\hline $\begin{array}{l}\text { Benzein, Johansson, } \\
\text { Årestedt, Berg \& } \\
\text { Saveman (2008) }\end{array}$ & Sweden & Registered nurses & 634 & 4 point & 4 & $\checkmark$ & $\checkmark$ & $\checkmark$ & $\checkmark$ & $\checkmark$ \\
\hline $\begin{array}{l}\text { Skúladóttir, } \\
\text { Konráðsdóttir \& } \\
\text { Ágústsdóttir (2010) }\end{array}$ & Iceland & Unknown & 140 & 4 point & 4 & $\checkmark$ & No & No & No & No \\
\hline $\begin{array}{l}\text { Saveman, Benzein, } \\
\text { Engström \& Årestedt } \\
\text { (2011) }\end{array}$ & Sweden & $\begin{array}{l}\text { Nurse specialist } \\
\text { students (e.g } \\
\text { midwives) }\end{array}$ & 246 & 5 point & 4 & $\checkmark$ & $\checkmark$ & $\checkmark$ & $\checkmark$ & $\checkmark$ \\
\hline $\begin{array}{l}\text { Sveinbjarnardottir, } \\
\text { Svavarsdottir \& } \\
\text { Saveman (2011) }\end{array}$ & Iceland & Psychiatric nurses & 81 & 4 point & 4 & No & No & No & No & No \\
\hline Oliveira et al. 2011 & Portugal & $\begin{array}{l}\text { Primary healthcare } \\
\text { nurses }\end{array}$ & 136 & 4 point & 3 & $\checkmark$ & $\checkmark$ & No & No & No \\
\hline Silvia et al. 2015 & Portugal & $\begin{array}{l}\text { Primary healthcare } \\
\text { nurses }\end{array}$ & 871 & 4 point & 3 & $\checkmark$ & No & No & No & No \\
\hline Blöndal et al. 2014 & Iceland & Surgical nurses & 181 & 4 point & 4 & $\checkmark$ & No & No & No & No \\
\hline Angelo et al. 2014 & Brazil & Paediatric nurses & 50 & 4 point & 3 & No & No & No & No & No \\
\hline $\begin{array}{l}\text { Linnarsson, Benzein \& } \\
\text { Årestedt (2015) }\end{array}$ & Sweden & $\begin{array}{l}\text { Emergency depart. } \\
\text { nurses }\end{array}$ & 457 & 5 point & 4 & $\checkmark$ & No & No & No & No \\
\hline Hsiao \& Tsai (2015) & Taiwan & Psychiatric nurses & 175 & 5 point & 4 & $\checkmark$ & No & No & No & No \\
\hline $\begin{array}{l}\text { Fernandes, Pereira } \\
\text { Gomes, Martins, } \\
\text { Pereira Gomes \& } \\
\text { Hisako (2015) }\end{array}$ & Portugal & $\begin{array}{l}\text { General hospital } \\
\text { nurses }\end{array}$ & 160 & 4 point & 3 & $\checkmark$ & No & No & No & No \\
\hline $\begin{array}{l}\text { Pascual Fernández al. } \\
2015\end{array}$ & Spain & Paediatric nurses & 186 & 4 point & 4 & $\checkmark$ & $\checkmark$ & $\checkmark$ & No & No \\
\hline Author blinded 2017 & & & 425 & 5 point & 4 & No & No & No & No & No \\
\hline
\end{tabular}




\begin{tabular}{|c|c|c|c|c|c|c|c|c|c|c|}
\hline Author & Country & Nurses sample & & $\begin{array}{l}\text { Likert } \\
\text { scale }\end{array}$ & $\begin{array}{l}\text { Numberof } \\
\text { Subscales }\end{array}$ & $\begin{array}{l}\text { Cronbach's } \\
\text { alpha's }\end{array}$ & $\begin{array}{c}\text { Factor } \\
\text { loadings }\end{array}$ & $\begin{array}{c}\text { Scale } \\
\text { dimensions }\end{array}$ & $\begin{array}{l}\text { Distribution } \\
\text { of scores }\end{array}$ & $\begin{array}{c}\text { Item total } \\
\text { correlations }\end{array}$ \\
\hline $\begin{array}{l}\text { Gusdal, Josefsson, } \\
\text { Thors Adolfsson \& } \\
\text { Martin (2017) }\end{array}$ & Sweden & Heart failure nurses & 303 & 5 point & 4 & $\checkmark$ & No & No & No & No \\
\hline $\begin{array}{l}\text { Mackie, Marshall, } \\
\text { Mitchell \& Ireland } \\
\text { (2018) }\end{array}$ & Australia & $\begin{array}{l}\text { General hospital } \\
\text { nurses }\end{array}$ & 212 & 5 point & 4 & $\checkmark$ & $\checkmark$ & $\checkmark$ & No & $\checkmark$ \\
\hline
\end{tabular}

(2018) 
To use the FINC-NA instrument in follow-up intervention research to measure changes in nurses’ attitudes, the instrument needed to be translated and psychometrically evaluated in Dutch. This study is part of a research program with the focus on family care interventions aiming to improve collaboration between family caregivers and nurses in hospitals, as well as in home health care. The use of a tested FINC-NA is needed to be able to measure changes in nurses' attitudes in follow-up pre- post intervention research, and to identity differences in groups.

Psychometric properties are important for assessing the validity and reliability of instruments in nursing research (Polit \& Tatano Beck, 2010). Psychometric properties most commonly investigated in nursing research are internal consistencies by Cronbach's alpha to quantify the internal reliability of a scale or subscale and factor analysis to assess the dimensionality of a scale (Nunnally \& Bernstein, 1994). As indicated in Table 1, many studies have reported various psychometric properties of the FINC-NA instrument. The most commonly reported is the internal consistency using the Cronbach's alpha of the FINC-NA scale and subscales (11 out of 15 studies). Five studies reported scale dimensionality of the FINC-NA based on confirmative as well as explorative methods of factor analysis. Two studies reported a score distribution of the items by the standardized response mean which is important for assessing the concept of the responsiveness of the items. Finally, three studies reported itemtotal correlations to evaluate the discrimination ability of the items.

The psychometric properties of studies exploring the FINC-NA in Table 1 are all based on classical test theories (Nunnally \& Bernstein, 1994; Polit \& Tatano Beck, 2010). Until recently, the Rasch type of models (Rasch, 1960) were not used to investigate scale properties. Such models represent constructs as latent traits allowing for a more detailed investigation of item and scale performance compared to the classical test theory and are beneficial for reviewing the psychometric properties of existing ordinal scales (Tennant \& Conaghan, 2007). 
Classical Test Theories do not evaluate instruments' psychometric properties of monotonicity, discrimination capacities of items, or item information curves per subscale (Masters, 1982). The Generalized Partial Credit Model (GPCM), an extension of the Rasch model, was therefore used to evaluate these missing psychometric properties of the FINC-NA instrument (Masters, 1982). This method is useful for reviewing the psychometric properties of ordinal scales (Tennant \& Conaghan, 2007) and allows for a more rigorous examination of measurement instruments in nursing (Hagquist, Bruce, \& Gustavsson, 2009).

The GPCM assumes that each nurse has a fixed value on a latent trait continuum. Latent trait values determine the probability of specific nurse responses on categories of items belonging to a subscale (Masters, 1982). Monotonicity refers to the models' assumption that, when there is an increase in nurses' positive attitudes towards families, there should also be an increase in the proportion of nurses with a high latent trait score. Items that violate this assumption might not optimally measure the construct to be evaluated. A discrimination parameter is important for examining the degree to which each item discriminates between nurses having different values on the trait (Masters, 1982). Item information curves demonstrate how much information each item contributes to values of the latent trait for each scale. By using the GPCM, more information can be generated on the variability of the scores (Li \& Baser, 2012). An application of the model thus facilitates detailed information on the variability of scores and their importance with respect to the latent attitude trait (Hagquist, et al., 2009).

Based on these results, we ascertained a need to further explore the psychometric properties of the FINC-NA. The aim of this study was to determine psychometric properties of the FINC-NA regarding dimensionality, score distribution, internal consistency, monotonicity, discrimination parameters, and item information curves of each subscale using the GPCM. 


\section{Method}

A cross-sectional design was used and data were collected with an online survey. Four general hospitals and one home healthcare organization in the northern part of the Netherlands participated in the study.

\section{Sample and Setting}

The sample consisted of 1,211 nurses; 403 hospital- and 808 home healthcare nurses. Participating hospital wards were cardiology (3), internal medicine (3), pulmonology (4), neurology (4), and one geriatric nursing ward. The home healthcare organization self-selected a region in the north of the Netherlands to participate in the study. Nurses had obtained an associate degree level 3 (a three-year course at a community college, without technical nursing interventions, like infusions), an associate degree level 4 (a four-year course at a community college, including technical nursing interventions), a bachelor degree, or master degree in nursing (Mistianen, Kroezen, Triemstra, \& Francke, 2011).

\section{Instrument}

The FINC-NA consists of 26 items divided into four subscales: Family as its own resource (Fam-OR) referring to families’ own resources for coping (four items); Family as a burden (Fam-B) referring to statements of experiencing family as a burden (four items); Family as a conversational partner (FAM-CP) referring to the acknowledgement of the patients' family members as conversational partners (eight items), and Family as a resource in nursing care (Fam-RNC) referring to a positive attitude towards families' presence in nursing care (ten items). In this study, the revised version of the FINC-NA five-point Likert scale was used with the response categories ‘strongly disagree’ to ‘strongly agree’ (Saveman, et al., 2011). The item scores range from 1 to 5 with total scale scores ranging from 26 - 130 for the total instrument. The higher the score, the more supportive nurses' attitudes are towards families, with the 
exception of the burden scale. The four 'negatively' formulated items of the subscale family as a burden were subsequently reversed in order to facilitate data analysis.

Translation of the instrument (linguistic validation). Written permission was granted by the original authors for the use and translation of the instrument. The original instrument was translated from Swedish into Dutch using the bidirectional translation method for linguistic-cultural adaptation (Wild, et al., 2005). Two independent professional translators provided the forward and back translation of the original instrument from Swedish into Dutch and from Dutch into Swedish. Reconciliation of the first translation into Dutch was discussed by the first author and two co-authors. One of the co-authors is a native Dutch speaker with excellent knowledge of the Swedish language. Some minor, mostly constructive, changes to some of the sentences were suggested by her during the back translation. All differences were discussed by the professional translators and the three authors of the article to reach consensus. Throughout the instrument, the term 'sjuke' (sick person) was changed into 'patient'.

\section{Data Collection}

The FINC-NA instrument was transferred into a web application that included demographic characteristics: age; gender; years of work experience; highest level of education in nursing; followed training in family care; knowledge of policy on family involvement being present in the organization; and prior experience as an informal caregiver with caring for a sick family member. A message containing a personalized link to the survey was sent to nurses' work email addresses. After two or four weeks, a reminder was automatically sent to all e-mail addresses in the event that no response was yet received. The web application had the ability to automatically send reminders after a set period of time to all e-mail addresses that had not responded yet. This process was blinded for all persons, including the researcher. Data were collected in 2015. 


\section{Ethical Considerations}

The Medical Ethics Committee of a Medical Medical Center Leeuwarden ruled that this study was not under regulation of the Medical Research Involving Human Subjects Act (Reference nWMO106). Permission to perform the study was granted by the directors of the participating organizations. Prior to the beginning of the study, nurses were informed about the purpose by their managers and through a newsletter. Nurses voluntarily participated in the study and gave their consent for participation and publication of the results before completing the online survey. Responses were received anonymously and, therefore, could not be traced back to individual persons. Results were processed anonymously.

\section{Data Analyses}

To investigate the dimensionality of the four-subscale structure, factor analysis was based upon Polychoric correlations as the items consist of ordered categories (Drasgow, 1986). From each subscale, confidence intervals of the eigenvalues from the Polychoric inter item correlations were computed. The number of eigenvalues significantly $>1$ were an indication for the dimensionality of subscales (Kaiser, 1960). For comparative purposes with other studies, both Cronbach’s alpha (Cronbach, 1951; Revelle \& Zinbarg, 2009) and ordinal coefficient alpha (Zumbo, Gadermann, \& Zeisser, 2007) were measured for internal consistency, with values >.7 considered acceptable (Nunnally \& Bernstein, 1994).

A one-dimensional (ordinal) factor analysis on Polychoric correlations per subscale (Basto \& Pereira, 2012) was used to investigate the size of loadings, that is the degree of association of the items with the latent trait (factor). Items with factor loadings of $\geq 0.32$ (Tabachnick and Fidell, 2007) were considered for interpretation in this study as follows: > 0.71 (excellent); > 0.63 (very good); > 0.55 (good); > 0.45 (fair); $\geq 0.32$ (poor). In addition, percentages of responses per category (1. Strongly disagree -5 . Strongly agree) were estimated for all of the items to assess the response distribution over the categories. 
The Generalized Partial Credit Model was used to determine the monotonicity, discrimination parameter, and information of items per subscale (Masters, 1982). Monotonicity implies that increasing levels across the response categories for each item should be reflected in the data, implying that the threshold estimates located on the latent trait must appear in the same order as the manifest categories (Andrich, 1978). In our measurement of nurses' attitudes towards the importance of families, each item consisted of five ordered response categories separated by four category thresholds on the latent attitude trait estimated by the model. These category steps govern the probability of scoring 1 rather than 0,2 rather than 1 , 3 rather than 2 , and 4 rather than 5 on each item. The category thresholds are values on the latent trait that may be conceived as step parameters, as each nurse steps through the response categories (1-5) of each item and stops at the position nearest to his/her trait level. In this way, latent trait values determine the probability of specific responses on categories of items belonging to a subscale. The positions of the step parameters on the latent trait indicate whether and how the categories of each item contribute to the monotonicity of the latent attitude trait.

The degree to which each item discriminates between nurses with different values on the trait is given by its slope, also referred to as the discrimination parameter (Masters, 1982). The greater the discrimination parameter, the better an item performs in discriminating between nurses with different attitudes. The amount of information that each item contributes to values of the latent trait is expressed by the item information curves for each scale. The models are estimated by the marginal maximum likelihood (Rizopoulos, 2006) using the programming language R (R Core Team, 2016).

To explore the construct validity of the four subscales 'Family as a conversational partner', 'Family as its own resource', 'Family as a burden' and 'Family as a resource in nursing care', factor and latent trait scores and their correlations were estimated for each subscale. 
Respondents who had more than 5 items (25\%) of the 26 items missing, or those who had more than $25 \%$ missing on a subscale were omitted for further analysis. Missing values were replaced with SPSS by the method of series means (Downey \& King, 1998).

\section{Results}

A total of 597 (49\%) nurses responded to the online survey. The responses of 28 (4.7\%) nurses were omitted because more than 5 items were missing of the total scale, resulting in a total number of 569 responses that were suitable for further analysis. Only four (.7\%) respondents had one missing item at random, concerning items B2, CP2, OR2 and RNC8. These missing items were replaced by the series mean.

Table 2 illustrates the sample characteristics of the nurses. Table 3 summarizes the psychometric properties of the items and subscales of the FINC-NA (Supplementary file 1). The subscales are shown with their items in chronological order as they appear in the questionnaire and are expressed in truncated sentences to save space. Items are listed by subscale letters and number, i.e., item 1 from 'Family as its own resource' is referred to by OR1. 
Table 2. Nurses' characteristics

M (SD)

\begin{tabular}{lcc}
\hline Age & & $43.5(12.8)$ \\
\hline Years of work experience & & $19.3(12.2)$ \\
& Nemale & (\%) \\
\hline Gender & Male & $538(95)$ \\
& Yes & $31(5)$ \\
\hline Policy present on families & No & $253(45)$ \\
\hline Training in family nursing & Yes & $316(55)$ \\
\hline Informal caregiving experience & No & $87(15)$ \\
& Yes & $482(85)$ \\
\hline Highest level of education in & No & $372(65)$ \\
nursing* (n=560) & Associate Degree level 3* & $197(35)$ \\
& Associate Degree level 4** & $143(25)$ \\
& Bachelor Degree & $252(45)$ \\
& Master Degree & $150(27)$
\end{tabular}

* an associate degree level 3 (a three-year course at a community college without technical nursing interventions, such as infusion and injections, but including medication administration)

**an associate degree level 4 (a four-year course at a community college, including technical nursing interventions)

Subscale Family as its Own Resource. The largest two eigenvalues and their confidence intervals of the subscale 'Family as its own resource' (Fam-OR) were 2.37 (95\% CI: 2.21-2.51) and 0.64 (95\% CI: .57-.74), respectively, indicating that this subscale is one dimensional. Table 3 shows the percentages per category responses; all responses are fairly well symmetrically distributed over the categories, although the percentages for Category 1 are somewhat smaller than for Category 5 and percentages of Category 4 are somewhat higher than for Category 2. The ordinal and Cronbach’s alpha coefficients of .77 and .73, respectively, are fairly large considering that there are four items in this subscale. Alpha decreases substantially if an item is deleted (e.g., item 1). 


\section{Table 3. Psychometric properties of the FINC-NA}

\begin{tabular}{|c|c|c|c|c|c|c|c|c|c|c|c|c|c|c|}
\hline \multirow[b]{2}{*}{ Subscales } & \multicolumn{5}{|c|}{$\begin{array}{c}\text { Percentages per } \\
\text { category of response }\end{array}$} & \multirow[t]{2}{*}{$\begin{array}{c}\alpha \text { if } \\
\text { deleted }\end{array}$} & \multirow{2}{*}{$\begin{array}{c}\begin{array}{c}\text { Factor } \\
\text { Loadings }\end{array} \\
\text { Estimate }\end{array}$} & \multicolumn{4}{|c|}{$\begin{array}{c}\text { Generalized Partial Credit Model } \\
\text { coefficients }\end{array}$} & \multirow[t]{2}{*}{$\begin{array}{c}\text { Discr. } \\
\text { parameter }\end{array}$} & \multicolumn{2}{|c|}{ Item information } \\
\hline & 1 & 2 & 3 & 4 & 5 & & & Step 1 & Step 2 & Step 3 & Step 4 & & negative & positive \\
\hline \multicolumn{15}{|l|}{ Family as own resource (OR) } \\
\hline 1. Encourage fam to use own resources & 3 & 14 & 37 & 34 & 12 & .65 & .70 & -2.46 & -1.42 & .09 & 1.61 & 1.29 & 3.13 & 2.01 \\
\hline 2. I see myself as resource for fam to cope & 2 & 9 & 31 & 42 & 17 & .67 & .67 & -2.66 & -1.80 & -.40 & 1.38 & 1.17 & 3.16 & 1.54 \\
\hline 3. I see fam as co-operating partners & 3 & 14 & 38 & 34 & 11 & .68 & .64 & -2.57 & -1.52 & .17 & 1.88 & 1.04 & 2.48 & 1.67 \\
\hline 4. I ask fam how I can to support them & 5 & 15 & 33 & 33 & 16 & .67 & .68 & -2.14 & -1.32 & .01 & 1.37 & 1.07 & 2.64 & 1.65 \\
\hline Ordinal alpha total subscale & & & & & & .77 & & & & & & & & \\
\hline Cronbach's alpha total subscale & & & & & & .73 & & & & & & & & \\
\hline \multicolumn{15}{|l|}{ Family as a burden (B) } \\
\hline 1. Presence of fam makes me feel checked up & 1 & 8 & 24 & 36 & 31 & .61 & .78 & -2.94 & -1.57 & -.61 & .52 & 1.83 & 5.52 & 1.81 \\
\hline 2. Presence of fam. makes me feel stressed & 1 & 3 & 21 & 34 & 41 & .60 & .83 & -2.45 & -2.09 & -.82 & .18 & 2.40 & 7.90 & 1.72 \\
\hline 3. Presence of fam. holds me back in work & 1 & 5 & 23 & 41 & 30 & .66 & .61 & -3.26 & -2.39 & -.91 & .70 & .94 & 2.80 & 0.94 \\
\hline 4. I don't have time to take care of fam. & 2 & 7 & 26 & 34 & 31 & .73 & .46 & -3.74 & -3.17 & -.63 & .39 & .52 & 1.49 & 0.56 \\
\hline Ordinal alpha total subscale & & & & & & .76 & & & & & & & & \\
\hline Cronbach’s alpha total subscale & & & & & & .71 & & & & & & & & \\
\hline \multicolumn{15}{|l|}{ Family as conversational partner (CP) } \\
\hline 1. I invite fam for convers. at end of care period & 11 & 21 & 35 & 23 & 10 & .70 & .62 & -1.56 & -.87 & .76 & 1.88 & .83 & 1.65 & 1.65 \\
\hline 2. I ask fam take part in discussions at start care & 12 & 23 & 31 & 19 & 15 & .70 & .63 & -1.58 & -.59 & .84 & .98 & .77 & 1.53 & 1.53 \\
\hline 3. I find out what fam members a patient has & 5 & 21 & 31 & 30 & 13 & .69 & .70 & -2.35 & -.79 & .17 & 1.50 & 1.08 & 2.45 & 1.87 \\
\hline 4. I invite fam speak about changes in condition & 1 & 2 & 17 & 39 & 41 & .72 & .46 & -2.67 & -4.00 & -1.70 & .05 & .60 & 1.92 & .47 \\
\hline 5. I invite fam to speak when planning care & 11 & 30 & 38 & 15 & 6 & .72 & .48 & -2.35 & -.51 & 1.94 & 2.43 & .57 & .97 & 1.28 \\
\hline 6. Important to find out who fam members are & 1 & 4 & 12 & 33 & 50 & .73 & .42 & -3.25 & -3.29 & -2.27 & -.77 & .49 & 1.63 & .32 \\
\hline
\end{tabular}




\begin{tabular}{|c|c|c|c|c|c|c|c|c|c|c|c|c|c|c|}
\hline \multirow[b]{2}{*}{ Subscales } & \multicolumn{5}{|c|}{$\begin{array}{c}\text { Percentages per } \\
\text { category of response }\end{array}$} & \multirow[t]{2}{*}{$\begin{array}{c}\alpha \text { if } \\
\text { deleted }\end{array}$} & \multirow{2}{*}{$\begin{array}{c}\text { Factor } \\
\text { Loadings }\end{array}$} & \multicolumn{4}{|c|}{$\begin{array}{c}\text { Generalized Partial Credit Model } \\
\text { coefficients }\end{array}$} & \multirow[t]{2}{*}{$\begin{array}{c}\text { Discr. } \\
\text { parameter }\end{array}$} & \multicolumn{2}{|c|}{ Item information } \\
\hline & 1 & 2 & 3 & 4 & 5 & & & Step 1 & Step 2 & Step 3 & Step 4 & & negative & positive \\
\hline 7. I invite fam to actively take part in care & 9 & 26 & 40 & 20 & 5 & .71 & .56 & -2.13 & -.79 & 1.21 & 2.61 & .76 & 1.43 & 1.62 \\
\hline 8. Conversation at start of care saves time & 5 & 13 & 34 & 39 & 9 & .72 & .46 & -2.55 & -2.16 & -.14 & 3.04 & .57 & 1.34 & .90 \\
\hline Ordinal alpha total subscale & & & & & & .77 & & & & & & & & \\
\hline Cronbach's alpha total subscale & & & & & & .74 & & & & & & & & \\
\hline \multicolumn{15}{|l|}{ Family as resource in nursing care (RNC) } \\
\hline 1. Presence of fam eases my workload & 3 & 12 & 54 & 27 & 4 & .80 & .64 & -2.20 & -1.75 & .78 & 2.61 & 1.24 & 2.70 & 2.25 \\
\hline 2. Presence of fam gives me feeling of security & 13 & 26 & 48 & 10 & 3 & .81 & .49 & -1.67 & -1.03 & 2.75 & 2.73 & .66 & 1.10 & 1.54 \\
\hline 3. Presence of fam is important to me as nurse & 1 & 7 & 27 & 41 & 24 & .79 & .73 & -2.68 & -1.86 & -.56 & .85 & 1.54 & 4.44 & 1.72 \\
\hline 4. Fam should be invited take active part in care & 1 & 8 & 38 & 32 & 21 & .81 & .60 & -3.35 & -2.29 & .08 & .99 & .94 & 2.49 & 1.29 \\
\hline 5. Fam should be invited in active planning care & 4 & 19 & 40 & 27 & 10 & .81 & .58 & -2.70 & -1.26 & .63 & 1.96 & .81 & 1.77 & 1.46 \\
\hline 6. Good relations fam give me job satisfaction & 1 & 1 & 14 & 36 & 48 & .81 & .57 & -2.08 & -3.72 & -1.59 & -.25 & .89 & 3.03 & .54 \\
\hline 7. Getting involved gives me feelings useful & 2 & 4 & 28 & 45 & 21 & .81 & .61 & -1.71 & -2.94 & -.73 & 1.26 & .90 & 2.56 & 1.04 \\
\hline 8. Gain worthwhile knowledge from fam to use & 2 & 7 & 26 & 45 & 20 & .80 & .68 & -2.48 & -1.82 & -.64 & 1.16 & 1.28 & 3.61 & 1.51 \\
\hline 9. Presence of fam important for fam self & 1 & 4 & 28 & 45 & 22 & .81 & .49 & -4.13 & -3.34 & -.85 & 1.34 & .70 & 2.00 & .80 \\
\hline 10. It is important to spend time with fam & 1 & 3 & 22 & 47 & 27 & .80 & .64 & -2.31 & -2.89 & -1.00 & .81 & 1.20 & 3.65 & 1.16 \\
\hline Ordinal alpha total subscale & & & & & & .85 & & & & & & & & \\
\hline Cronbach's alpha total subscale & & & & & & .82 & & & & & & & & \\
\hline
\end{tabular}

Discr. Parameter: discriminatory parameter. 
Factor loadings for all of the items in this subscale are very good; between .64 and .70. The location parameters are low for category step 1/2, large for step 4/5, and all increase monotonically for each item with the latent Fam-OR trait values for nurses. The absolute values of category step $1 / 2$ are somewhat larger than those for step $4 / 5$, which is in accordance with the size of the percentages of nurse responses in Categories 1 and 5.

Table 3 also shows that the discrimination parameters from the GPCM are relatively equal and large in size $(1.04 ; 1.29)$. This is also reflected in the item information curves in Figure 1A, indicating that these are high for a broad range of latent trait values. Each of the items contains approximately an equal amount of information on the latent Fam-OR trait. This is in line with the information in Table 3 that depicts that the amount of negative and positive information is comparable between the items of this subscale, although with slightly more information on negative trait values.

The similarity and coverage of the Fam-OR information curves indicate that these items provide an equal amount of information on the latent trait. With discrimination parameters of 1.04 and higher, all items discriminate well between the different trait levels; discriminate between nurses with low, middle, and large values on the latent Fam-OR trait. Category step locations of the items are homogeneous in the sense of being well spread over the range of the Fam-OR trait, showing that the items adequately measure the different trait levels.

Subscale Family as a Burden. The largest two eigenvalues and their confidence intervals of the 'family as a burden' were 2.37 (95\% CI: 2.22-2.53) and 0.73 (95\% CI: .65-.84), respectively, and indicate that the subscale is one dimensional. Table 3 shows that all items of this subscale are asymmetrically distributed with very small response percentages on Categories 1 (range $.1 ; .2$ ) and 2 (range $.3 ; .8$ ) and relative large response percentages on Categories 4 (range .34; .41) and 5 (range .30; .41) (Table 3). The ordinal and Cronbach’s alpha coefficients of .76 and .71, respectively, are relatively large considering that there are four items in this 
scale. The Cronbach's alpha increases to .73 if item B4 (I don't have time to take care of families) is deleted and decreases substantially if item B1 or B2 is deleted. Factor loadings are excellent for items B1 and B2 (.83; .78), and good to fair for item B3 and B4 (.61; .46), respectively.

As shown in Table 3, location parameters are low for category step 1/2 and close to zero for step $4 / 5$ and monotonically increase for each item as the value on the latent Fam-B trait increases. The small step values of the location values for category $4 / 5$ correspond with the larger percentages of responses on Category 5 (Table 3). This indicates that nurses with latent scores close to zero have a relatively high probability to respond to Category 5 . The absolute values of step location $1 / 2$ are larger than those for location $4 / 5$, which accords with the smaller percentages found in Category 1 compared to 5.

The discrimination parameters for this subscale are substantial for items B1 and B2 (1.83; 2.40), moderate for item B3 (.94), and small for item B4 (.52) (Table 3). The item information curve in Figure 1B shows that items B1 and B2 contribute three to four times more information on the latent FamB trait than items B3 and B4. This follows also from the amount of information being higher on the negative part than that on the positive, especially for items B2 (7.90-1.72) and B1 (5.52-1.81), respectively (see Table 3).

Subscale Family as a Conversational Partner. The largest two eigenvalues of the subscale ‘family as conversational partner' (Fam-CP) were 3.10 (95\% CI: 2.83-3.40) and 1.03 (95\% CI: .97-1.20), respectively, indicating that this scale is one dimensional. Table 3 shows that five out of eight items (CP1, CP2, CP3, CP5, CP7) have the largest percentages of responses on Category 3 with small percentages on the extremes and symmetrically distributed responses over these categories. Items CP4 and CP6 are asymmetrically distributed having 3\% and $5 \%$ responses on Category 1 or 2 and $80 \%$ and $83 \%$ of their responses on Category 4 or 5 , respectively, making the responses on these items skewed to the right. Coefficient alphas of .77 
and .74 are acceptable but not very large considering that there are eight items in this subscale. Items $1,2,3$, and 7 of the Fam-CP subscale show good to very good factor loadings (.62; .63; $.70 ; .56)$ contrary to that of item $6(.42)$.

The item category responses in Table 3 are fairly symmetrically distributed and have step location parameters which increase monotonically with the size of the latent Fam-CP variable as was intended by the category ordering. Item CP4 and CP6 are exceptions in violating the category order (monotonicity). The discrimination parameters shown in Table 3 are moderate (.76 - 1.08) for items CP1, CP2, CP3, and CP7 and somewhat small (.49 - .60) for the remaining items.

The information curves in Figure 1C show that items CP1, CP2, CP3, and CP7 contain an equal amount of information on the latent Fam-CP trait and are fairly symmetrically distributed. Items CP4 and CP6, on the other hand, have almost no information on positive latent FamCP trait scores which is also illustrated by the amount of information of these items on positive latent scores in Table 3, CP6 (1.63; -.32.), and CP4 (1.92; -.47).

Subscale Family as a Resource in Nursing Care. Eigenvalues and their confidence intervals of the 'family as a resource in nursing care' (Fam-RNC) subscale with the largest two eigenvalues of 4.38 (95\% CI: 4.03-4.73) and 1.06 (95\% CI: 0.98-1.25), respectively, indicate that the scale is one dimensional. Table 3 shows that four of the ten items of this scale are somewhat symmetric having the largest proportion of responses in Category 3, five items are less symmetrical with the largest percentages in Category 4. Item RNC6 (A good relationship with family members gives me job satisfaction) behaves very asymmetrically with the largest proportion in Category 5.

The alpha coefficients of .85 and .82 are sufficient and the Cronbach’s alpha slightly decreases if any of the items are deleted. Factor loadings are good to excellent with those of items RNC2 and RNC9 being smaller (.49). The step location parameters of all items increase 
monotonically with the value of the latent FamRNC trait except for step 2/3 of RNC items 6, 7, and 10 and step 3/4 of item RNC2. The discrimination parameters are larger than 1.20 for RNC items 1, 3, 8, and 10 while the others are moderate between .66 and .94 (table 3).

The item information curve in Figure 1D shows that item RNC3 contains twice the amount of information on the latent Fam-RNC trait compared to RNC items 2 and 9 with discrimination parameters of .66 and .70, respectively. The negative step locations of item RNC6 suggest that it mainly provides information on negative latent Fam-RNC scores for nurses. This is also seen in the amount of information item RNC6 depicts in Table 3, with 3.03 negative information and .52 positive information.

\section{Exploration of subscale constructs}

Table 4 indicates the correlations of the latent trait scores of nurses'attitudes towards the importance of families in nursing care from a polychoric factor correlations as well as the generalized partial credit analysis. The lower triangle beneath the diagonal on the left side of the table gives the polychoric correlations, and the upper triangle above the diagonal on the right side are those from the GPCM. In both models, the correlations of the latent factors are all positive and pointing in the same direction. The subscale Fam-B has a small positive correlation with each of the other three subscales. In addition, the inter-correlations between the subscales Fam-OR, Fam-RNC, and Fam-CP latent traits are substantial. 
Table 4. Correlations between the subscales using Polychoric correlations and Generalized Partial Credit Model

Generalized Partial Credit Model

FamB FamOR FamCP FamRNC

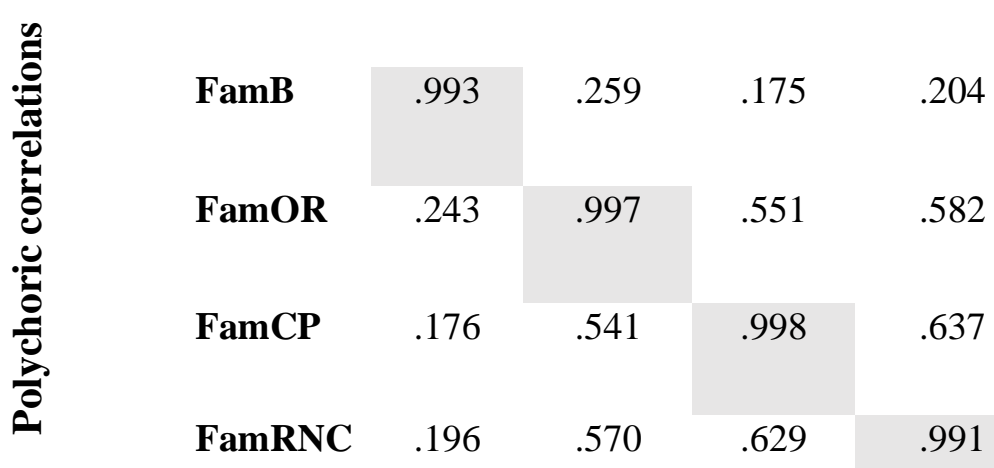

\section{Discussion}

This study demonstrates that the Dutch FINC-NA has a unidimensional structure for each subscale. Results showed good to excellent factor loadings for the majority of items of each subscale (Tabachnick \& Fidell, 2007). Score distributions exhibit responses on all Likert categories. We found that item categories increase monotonically with increasing latent trait and that the majority of items contain a sufficient amount of information on the trait.

The unidimensional four-subscale structure of the FINC-NA that was found in this study is consistent with findings of previous studies (Mackie, et al., 2017; Pascual Fernández et al., 2015; Saveman, et al., 2011). In contrast to these studies, we investigated the dimensionality per subscale. Finding a four-subscale structure using a different method of analysis adds to the evidence for such a structure. These results are in contrast with findings of Oliveira et al. (2011) pertaining to a three-subscale instrument of the FINC-NA based on theoretical content, factor loadings, and internal consistency of each factor without deleting items. The findings of our 
study indicate that a four-subscale structure of the FINC-NA is the most interpretable to be employed in future studies.

Internal consistencies of the subscales in this study were moderate to strong (Nunnally \& Bernstein, 1994) and Cronbach’s alphas were slightly lower compared to those found in other studies (Gusdal, Josefsson, Thors Adolfsson, \& Martin, 2017; Rahmqvist, et al., 2014; Saveman, et al., 2011). The two smaller subscales, Fam-OR and Fam-B, show adequate reliability especially compared to those of the eight-item subscale of Fam-CP. This may imply that fewer items per subscale are able to give the same amount of information. The internal consistency of the total score of .88 shows a strong reliability of the total FINC-NA scale and supported its use in further studies.

All of the items in this study had factor loadings $\geq .42$. These findings are in contrast with findings of, e.g., Mackie et al. (2017), who found four items with factor loadings $<0.32$; OR2, CP3, CP6, and CP8, respectively. In our study, factor loadings for these items were higher; .67 (OR2); .70 (CP3); .42 (CP6), and .46 (CP8), respectively. These different findings may reflect cultural differences between countries.

Score distributions show responses on all Likert categories which supports the application of a five-point Likert scale. As was found by Saveman et al. (2011), a number of items show ceiling effects that do not adequately measure the right side of the latent trait. For example, item B2 (The presence of family members makes me feel stressed) has a score distribution of $1,3,21,34$, and 41, respectively, as shown in Table 3. Nurses that scored a five on these items may possibly have had an even higher latent trait value. In this case, it might be relevant to add a stronger formulated item in order to differentiate between nurses who have an even higher latent trait score on this concept which would result in expanded scale measurement properties. 
Generalized Partial Credit coefficients of the majority of items indicate monotonicity as the model assumes, that is, most item categories indeed increase monotonically with increasing latent trait values. An example of an item that violates this assumption of monotonicity is RNC6 (A good relationship with family members gives me job satisfaction). As shown in Table 3, the GPCM coefficients of this item range from -2.08 to -0.25 , measuring only latent trait values of nurses on the left side. This is also reflected by the item information scores of 3.03 on the negative side and 0.54 on the positive side (Table 3) and the item information curve of item RNC6 in Figure 1D. Thus, this item primarily provides information on the left extreme of the latent trait and does not appear to contribute to discriminating between nurses with positive responses on this latent Fam-RNC variable (Comrey \& Lee, 1992). This suggests that omitting this item would result in only a minimal loss of information regarding Dutch nurses.

We were able to demonstrate that most items of the FINC-NA instrument discriminate well between the latent trait scores of nurses by their discrimination parameters, for example, all items of the subscale family as its own resource (FamOR) subscale have a discrimination parameter larger than 1 (Table 3). Item information curves of the subscale 'Family as a conversational partner' in Figure 1C illustrate that some items provide considerably more information on the nurses' latent traits than others. An example is item CP6 (It is important to find out what family members a patient has) which gives half of the amount of information on the nurses' latent trait compared to item CP3 (I always find out what family members a patient has). This might suggest that, with less items, a comparable amount of information could be generated on the concept to be measured.

To the best of our knowledge, this is the first study to apply a Generalized Partial Credit Model to the FINC-NA instrument. Classical Test Theory for reliability and confirmatory factor analysis are based on covariances of items and provide only indirect information about values of the latent trait. By employing this method, the information from the analysis better accords 
with the actual nurse responses (Yang \& Kao, 2014). Therefore, this method of analysis generated new information on choice options of the instrument, allowing for detailed insight into the construct and content of the instruments' items. This specific information was generated on item level which allowed for more efficient adjustments to the FINC-NA instrument, if desirable. The results of this study, as well as previous studies (Benzein, et al., 2008; Saveman, et al., 2011), show strong evidence for the four-subscale structure of the FINC-NA. Use of the four-subscale structure, as well as the total scale score is therefore recommended for future studies.

Involving families in nursing care is an important development worldwide, and it is important that nurses' attitudes can be measured with an instrument that is valid and reliable across countries. By using detailed scale analysis more insight is given into how items and subscales of the FINC-NA behave, resulting in more detailed insight into perception of nurse attitudes towards the importance of families in nursing care. These results can be relevant for other countries who are interested in scale validation, for example countries as shown in Table 1. To generate additional in-depth information on how the FINC-NA instrument behaves at item level in other countries, researchers are invited to validate the FINC-NA in their countries and to apply the Generalized Partial Credit Model as a useful method of analysis. A validation study could then be performed to investigate linguistic and cultural issues, by comparing two or more lists in an international context in order to investigate the possibility of a more generic instrument instead of nation-based instruments.

\section{Strengths and limitations}

A strength of this study was the large sample size of nurses and nursing aides who work with families of elderly patients in a hospital or in-home health care; a sample size of $>500$ is considered very good (Comrey \& Lee, 1992). A satisfactory response rate of $49 \%$ was reached, but if a larger group had responded it might have affected the results. The convenience sample 
can be seen as a limitation of this study. The home health care organization self-selected one of their regions because this organization was in the middle of a reorganization in the other regions. This could feasibly have led to some preselection. Also, measuring attitudes of nurses entails subjective responses and might provoke social desirable behaviour; possibly influencing the reliability of study results.

Since this is the first time the GPCM was employed in psychometric testing of the FINC-NA, a limitation of this study is the impossibility of comparing the results with other studies. An additional limitation of this study was that no comparison with other instruments measuring nurses' attitudes towards the importance of family in nursing care was undertaken in order to measure construct validity. This could be a suggestion for further research. This study, however, did explore construct validity by estimating factor scores and their correlations. Future studies need to evaluate the test-retest properties of this instrument. Previous studies determined a positive relationship between female gender and a more positive attitude towards families in nursing care (Rahmqvist Linnarsson, et al., 2014). Since only 5\% of the nurses’ population in this study were male, we did not differentiate between gender by Differential Item Functioning.

\section{Conclusion}

Findings of this study show that the FINC-NA instrument has good psychometric properties in the sense of reliability, unidimensionality, monotonicity, and information and, therefore, is recommended for future family nursing research on behalf of the measurement of effects of interventions and to measure changes in nurses' attitudes. By using an advanced method of analysis, we were able to generate detailed information on the psychometric properties of the FINC-NA instrument in a Dutch population of hospital and home healthcare nurses. Future 
research should focus on improving properties of the subscales and generalizability over countries.

\section{Conflict of interest}

The authors declare no conflict of interest with respect to the research, authorship, and/or publication of this article.

\section{Funding}

This research received no specific grant from any funding agency in the public, commercial, or not-for-profit sectors.

\section{Acknowledgement}

The authors would like to express their sincere appreciation to the nurses who participated in this study and the Martini Hospital, Medical Center Leeuwarden, Nij Smellinghe Hospital, Wilhelmina Hospital Assen, and Home Care Organization Icare for their cooperation.

\section{References}

Andrich, D. (1978). A binominal latent trait model for the study of Likert-style Attitude questionnaires. British Journal of Mathematical and Statistical Psychology, 31, 84-89. https://doi.org/10.1111/j.2044-8317.1978.tb00575.x

Angelo, M., Cruz, A. C., Mekitarian, F. F. P., Santos Cavalcante da Silva Dos, C., Martinho, M. J. C. M., \& Martins Ferreira Pereira da Silva, M. M. (2014). Actitudes de enfermeras sobre la importancia de las familias en los cuidados de enfermería en pediatría [Nurses' attitudes regarding the importance of families in pediatric nursing care.] Revista $\mathrm{Da}$ Escola De Enfermagem Da U S P, 48 Spec No, 74-79. http://dx.doi.org/10.1590/S0080623420140000600011

Basto, M., \& Pereira, J. M. (2012). An SPSS R-Menu for ordinal factor analysis. Journal of Statistical Software, 46, 1-29. https://doi.org/10.18637/jss.v046.i04 
Benzein, E., Johansson, P., Årestedt, K. F., Berg, A., \& Saveman, B. I. (2008). Families' importance in nursing care: Nurses' attitudes--an instrument development. Journal of Family Nursing, 14, 97-117. https://doi.org/10.1177/1074840707312716

Benzein, E., Johansson, P., Årestedt, K. F., \& Saveman, B. (2008). Nurses' attitudes about the importance of families in nursing care: A survey of Swedish nurses. Journal of Family Nursing, 14, 162-180. https://doi.org/10.1177/1074840708317058

Blöndal, K., Zoëga, S., Hafsteinsdottir, J. E., Olafsdottir, O. A., Thorvardardottir, A. B., Hafsteinsdottir, S. A., \& Sveinsdóttir, H. (2014). Attitudes of registered and licensed practical nurses about the importance of families in surgical hospital units: Findings from the Landspitali University Hospital Family Nursing Implementation Project. Journal of Family Nursing, 20, 355-375. https://doi.org/10.1177/1074840714542875

Bridges, J., Flatley, M., \& Meyer, J. (2010). Older people's and relatives’ experiences in acute care settings: Systematic review and synthesis of qualitative studies. International Journal of Nursing Studies, 47, 89-107. https://doi.org/10.1016/j.ijnurstu.2009.09.009

Chen, Y.-C., Chang, L.-C., Liu, C.-Y., Ho, Y.-F., Weng, S.-C., \& Tsai, T.-I. (2018). The roles of social support and health literacy in self-management among patients with chronic kidney disease. Journal of Nursing Scholarship, 50(3), 265-275. https://doi.org/10.1111/jnu.12377

Cronbach, L. J. (1951). Coefficient alpha and the internal structures of tests. Psychometrika, 16, 297-334. https://doi.org/10.1007/BF02310555

Comrey, A. L., \& Lee, H. B. (1992). A first course in factor analysis. Hillsdale, NJ: Erlbaum.

Downey, R. G., \& King, C. (1998). Missing data in likert ratings: A comparison of replacement methods. The Journal of General Psychology, 125, 175-191. https://doi.org/10.1080/00221309809595542 
Drasgow, F. (2004). Polychoric and polyserial correlations. In S. Kotz, C. B. Read, N. Balakrishnan, B. Vidakovic and N. L. Johnson, (Eds.), Encyclopedia of statistical sciences (pp. 68-74). Hoboken, NJ: Wiley.

Fernandes, C. S., Pereira Gomes, J. A., Martins, M. M., Pereira Gomes, B., \& Hisako, T. G. (2015). A Importância das Famílias nos Cuidados de Enfermagem: Atitudes dos Enfermeiros em Meio hospitalar/La Importancia de Las Familias en el Cuidado de Enfermería - Enfermeras Actitudes en el Hospital [The importance of families in nursing care: Nurses' attitudes in the hospital environment]. Revista De Enfermagem Referência, 4, 21-30. https://doi.org/10.12707/RIV15007

Gusdal, A. K., Josefsson, K., Thors Adolfsson, E., \& Martin, L. (2017). Nurses’ attitudes toward family importance in heart failure care. European Journal of Cardiovascular Nursing, 16, 256-266. https://doi.org/10.1177/1474515116687178

Hagquist, C., Bruce, M., \& Gustavsson, J. P. (2009). Using the Rasch model in nursing research: An introduction and illustrative example. International Journal of Nursing Studies, 46, 380-393. https://doi.org/10.1016/j.ijnurstu.2008.10.007

Hsiao, C., \& Tsai, Y. (2015). Factors associated with the perception of family nursing practice among mental health nurses in Taiwan. Journal of Family Nursing, 21, 508-528. https://doi.org/10.1177/1074840715606543

Kaiser, H. F. (1960). The application of electronic computers to factor analysis. Educational and Psychological Measurement, 20, 141-151. https://doi.org/10.1177/001316446002000116

Li, Y., \& Baser, R. (2012). Using R and WinBUGS to fit a generalized partial credit model for developing and evaluating patient-reported outcomes assessments. Statistics in Medicine, 31, 2010-2026. https://doi.org/10.1002/sim.4475 
Lindhardt, T., Nyberg, P., \& Rahm Hallberg, I. (2008). Collaboration between relatives of elderly patients and nurses and its relation to satisfaction with the hospital care trajectory. Scandinavian Journal of Caring Sciences, 22, 507-519. https://doi.org/10.1111/j.14716712.2007.00558.x

Linnarsson, J. R., Benzein, E., \& Årestedt, K. (2014). Nurses' views of forensic care in emergency departments and their attitudes, and involvement of family members. Journal of Clinical Nursing, 24, 266-274. https://doi.org/10.1111/jocn.12638

Luttik, M., Goossens, E., Ågren, S., Jaarsma, T., Mårtensson, J., Thompson, D. R., . . . Strömberg, A. (2017). Attitudes of nurses towards family involvement in the care for patients with cardiovascular diseases. European Journal of Cardiovascular Nursing, 16, 299-308. https://doi.org/10.1177/1474515116663143

Lowson, E., Hanratty, B., Holmes, L., Addington-Hall, J., Grande, G., Payne, S., \& Seymour, J. (2013). From 'conductor' to 'second fiddle': Older adult care recipients' perspectives on transitions in family caring at hospital admission. International Journal of Nursing Studies, 50, 1197-1205. https://doi.org/10.1016/j.ijnurstu.2012.02.005

Mackie, B. R., Marshall, A., \& Mitchell, M. \& Ireland, M. J. (2018). Psychometric testing of the revised "families' importance in nursing care - nurses' attitudes instrument". Journal of Advanced Nursing, 74, 482-490. https://doi.org/10.1111/jan.13442.

Masters, G. (1982). A Rasch model for partial credit scoring. Psychometrika, 47, 149-174. https://doi.org/10.1007/BF02296272

McCabe, N., Dunbar, S. B., Butler, J., Higgins, M., Book, W., \& Reilly, C. (2015). Antecedents of self-care in adults with congenital heart defects. International Journal of Cardiology, 201, 610-615. http://dx.doi.org/10.1016/j.ijcard.2015.08.125

Mistianen, P., Kroezen, M., Triemstra, M., \& Francke, A. L. (2011). Verpleegkundigen en verzorgenden in internationaal perspectief. Een literatuurstudie naar rollen en posities 
van beroepsbeoefenaren in de verpleging en verzorging [A nurse is not a nurse. Nurses and carers in an international perspective: A literature study into the roles and positions of professionals in nursing and care]. Utrecht, the Netherlands: Nivel. Retrieved from https://www.nivel.nl/sites/default/files/bestanden/rapport-verpleging-verzorginginternationaal-perspectief.pdf

Neumann, D., Lamprecht, J., Robinski, M., Mau, W., \& Girndt, M. (2018). Social relationships and their impact on health-related outcomes in peritoneal versus haemodialysis patients: A prospective cohort study. Nephrology Dialalysis Transplantation, 33, 1235-1244. http://dx.doi.org/10.1093/ndt/gfx361

Nunes Carramanho Gomes Martins Moreira, da Silva, da Silva Mendes, d. C., \& Ferreira Pereira, d. S. (2013). La familia en la atención primaria: Evaluación de las actitudes de los enfermeros. [The family in primary care: Characterization of nurses’attitudes.] Revista De Enfermagem Referência, 48, 19-28. https://doi.org/10.12707/RIII13105

Nunnally, J. C., \& Bernstein, I. H. (1994). Psychometric theory (3rd ed.). New York, NY: McGraw-Hill.

Oliveira, P. d. C. M., Fernandes, H. I. V., Vilar, A. I. S. P., Figueiredo, M. H. d. J. S., Ferreira, M. M. S. R. S., Martinho, M. J. C. M., . . Martins, Maria Manuela Ferreira P. da S. (2011). Atitudes dos enfermeiros face à família: validação da escala Families’ importance in nursing care - nurses' attitudes. [Attitudes of nurses towards families: Validation of the scale families' importance in nursing care-nurses' attitudes]. Revista Da Escola De Enfermagem Da U S P, 45, 1331-1337. http://dx.doi.org/10.1590/S008062342011000600008

Pascual Fernández, M. C., Ignacio Cerro, M. C., Cervantes Estévez, L., Jiménez Carrascosa, M. A., Medina Torres, M., \& García Pozo, A. M. (2015). Cuestionario para evaluar la importancia de la familia en los cuidados de enfermería. Validación de la versión 
española (FINC-NA). [Questionnaire to evaluate the importance of the family in nursing care. validation of the Spanish version (FINC-NA)]. Anales Del Sistema Sanitario De Navarra, 38, 31-39. https://doi.org/10.23938/ASSN.0051

Polit, D. F. \& Tatano Beck, C. (2010). Nursing research: Appraising evidence for nursing practice. (7th ed.) Philadelphia, PA: Wolters Kluwer Lippincott Williams \& Wilkins.

R Development Core Team. (2016). R: A language and environment for statistical computing. Vienna, Austria: R Foundation for Statistical Computing. http://www.R-project.org/

Rasch, G. (1960). Probabilistic models for some intelligence and attainment tests. Copenhagen, Denmark: Paedagogiske Instituut.

Revelle, W., \& Zinbarg, R.E. (2009). Coefficients Alpha, Beta, Omega, And the GLB: Comments on Sijtsma. Psychometrika, 47, 145-154. 10.1007/s11336-008-9102z

Rizopoulos, D. (2006). Ltm: An R package for latent variable modeling and item response theory analyses. Retrieved from https://www.jstatsoft.org/article/view/v017i05

Saveman, B., Benzein, E. G., Engström, Å. H., \& Årestedt, K. (2011). Refinement and psychometric reevaluation of the instrument: Families' importance in nursing care-nurses' attitudes. Journal of Family Nursing, 17, 312-329. https://doi.org/10.1177/1074840711415074

Skúladóttir, A., Konráðsdóttir, E., \& Ágústsdóttir, A. (2010). Spurningalisti til að meta viðhorf fagfólks til fjölskylduhjúkrunar. [Questionnaire to evaluate the attitude of professionals towards family nursing.] Tímarit hjúkrunarfræeinga [Nursing Magazine Analyses], 86, 6-10. https://doi.org/10.1111/j.1365-2850.2011.01744.x

Sveinbjarnardottir, E. K., Svavarsdottir, E. K., \& Saveman, B. (2011). Nurses attitudes towards the importance of families in psychiatric care following an educational and training intervention program. Journal of Psychiatric and Mental Health Nursing, 18, 895-903. https://doi.org/10.1111/j.1365-2850.2011.01744.x 
Tabachnick, B. G., \& Fidell, L. S. (2007). Principal components and factor analysis. Using multivariate statistics (4th ed.) Cambridge, United Kingdom: Pearson.

Tennant, A., \& Conaghan, P. G. (2007). The Rasch measurement model in rheumatology: What is it and why use it? when should it be applied, and what should one look for in a Rasch paper? Arthritis and Rheumatism, 57, 1358-1362. https://doi.org/10.1002/art.23108

Wassenaar, A., Schouten, J., \& Schoonhoven, L. (2014). Factors promoting intensive care patients' perception of feeling safe: A systematic review. International Journal of Nursing Studies, 51, 261-273. https://doi.org/10.1016/j.ijnurstu.2013.07.003

Wild, D., Grove, A., Martin, M., Eremenco, S., McElroy, S., Verjee-Lorenz, A., \& Erikson, P. (2005). Principles of good practice for the translation and cultural adaptation process for patient-reported outcomes (PRO) measures: Report of the ISPOR task force for translation and cultural adaptation. Value in Health: The Journal of the International Society for Pharmacoeconomics and Outcomes Research, 8, 94-104. https://doi.org/10.1111/j.1524-4733.2005.04054.x

Yang, F. M., \& Kao, S. T. (2014) Item response theory for measurement validity. Shanghai Archives of Psychiatry, 26, 171-177. https://doi.org/10.3969/j.issn.1002-

\section{$\underline{0829.2014 .03 .010}$}

Zumbo, B. D., Gadermann, A. M., \& Zeisser, C. (2007). Ordinal versions of coefficients alpha and theta for Likert rating scales. Journal of Modern Applied Statistical Methods, 6, 21-29. https://doi.org/10.22237/jmasm/1177992180 